\title{
新規異方導電性フィルムの開発
}

\author{
山口 美穂*, 江里口 冬樹*, 浅井 文輝 ${ }^{*}$, 堀田 祐治*
}

\section{Development of New Anisotropic Conductive Film}

Miho YAMAGUCHI*, Fuyuki ERIGUCHI* , Fumiteru ASAI* and Yuji HOTTA*

*日東電工株式会社基幹技術センター（テ567-8680 大阪付茨朴术下稔積1-1-2）

*Core Technology Center, NITTO DENKO CORPORATION (1-1-2 Shimohozumi, Ibaraki-shi, Osaka 567-8680)

\section{Abstract}

Anisotropic conducting adhesive technology for flip chip interconnection, being actively investigated now. The new kind of Anisotropic Conductive Film (ACF) we are now developing has the following features:

1. Minimum pitch between conductive material is $0.025 \mathrm{~mm}$

2. Conductive material consists of linear metal material (not used small conductive particles)

3. Adhesive material consists of thermoplastic resin

4. Conductive material coated by insulator, which is a high heat distortion resin, is completely separated from the adhesive.

Key Words: Anisotropic Conductive Film, Thermoplastic Resin, Linear Metal Material, Insulator

\section{1. 緒 言}

近年, 電子機器の高性能化, 軽薄短小化が進むにつれて, ベアチップをフェースダウンで直接基板に接続するフリッ プチップ実装技術が注目され，さまざまな検討，実用化が 開始されている。表 1 に日本電子機械工業会（EIAJ）が 1996年に発表したフリップチップ実装に関するロードマッ
プを示す。このロードマップは，今後，半導体装置の接続 端子が小面積, 狭ピッチ化し，また地球環境保全のため鉛 の使用が難しくなる流れの中で，バンプレスチップを使用 したフリップチップの実用化が進むと予想している。

我々は，2000年頃に実用期を迎えるフリップチップ用接 続材料としてファインピッチ接続可能な異方導電性フィル ム（ACF）の開発を行っている。ここでは, 高信頼性を

表1. フリップチップボンディング技術のロードマップ

\begin{tabular}{|c|c|c|c|c|c|}
\hline & 1996 & 1997 & 1998 & 1999 & 2000 \\
\hline ピッチ $(\mathrm{mm}) /$ ペリフェラル & 0.16 & 0.13 & 0.1 & 0.08 & 0.08 \\
\hline 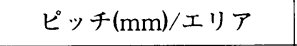 & 0.25 & 0.2 & $\leftarrow$ & $\leftarrow$ & 0.15 \\
\hline バンプサイズ(mm) & 80 & 60 & 50 & 40 & 30 \\
\hline バンプ高さ $(\mu \mathrm{m})$ & 80 & 60 & 50 & 40 & 30 \\
\hline \multirow{5}{*}{$\begin{array}{l}\text { 接続材料/ } \\
\text { バンプ材料 }\end{array}$} & \multicolumn{3}{|c|}{$\mathrm{SnPb} / \mathrm{Sn} / \mathrm{Pb}$} & \multicolumn{2}{|c|}{$\mathrm{Pb}$ Pリーはんだ/Pbフリーはんだ } \\
\hline & \multicolumn{3}{|c|}{ 導電ペースト/Au } & & \\
\hline & \multicolumn{5}{|c|}{$\mathrm{ACF} / \mathrm{Au}, \mathrm{Ni}$} \\
\hline & \multicolumn{3}{|c|}{ 熱or光硬化性絶緣樹脂/ $\mathrm{Au}$} & & \\
\hline & & & & \multicolumn{2}{|c|}{ 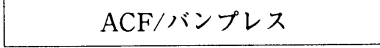 } \\
\hline \multirow{4}{*}{ バンプ形成方法 } & \multicolumn{4}{|c|}{ 電解めっき } & \\
\hline & & & & \multicolumn{2}{|c|}{ 無電解めっき } \\
\hline & \multicolumn{3}{|c|}{ スタッドバンプ } & & \\
\hline & & & & & バンプレス \\
\hline
\end{tabular}

EIAJ “半導体パッケージに関するロードマップ”より 
有する新規構造のACFの開発の現状について報告する。

\section{2. 新規ACFの開発目標}

従来のACFは, 接着性材料中に微少の導電性粒子が分 散されているが, ファインピッチ接続が難しく, 半導体素 子の接続端子としてバンプを用いる必要があるという問題 点がある。また, 接着材料が熱硬化性樹脂であるため, 室 温保存性の低下も問題となる。我々は, これらの問題点を 踏まえ, 前述したEIAJのロードマップを参考にし, 新規 ACFの開発目標を以下のように設定し, 開発を行ってい る。
(1)バンプレスチップと高密度プリント配線板とを接続
(2)高信頼性
(3)リペア可能
(4)室温保存性

\section{3. 新規ACFの構造}

上記の開発目標を実現するため, 図 1 に示すような構造 のACFを開発した。実際の表面写真を図 2 および図 3 に 示す。

この構造の特徵を以下に示す。

(1)導電性材料は, 銅線 (微少導電性粒子は使用せず),

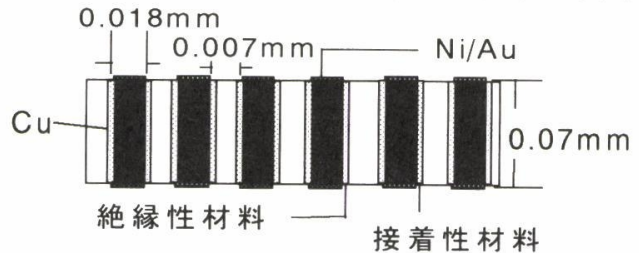

図1. 新規ACFの断面構造例

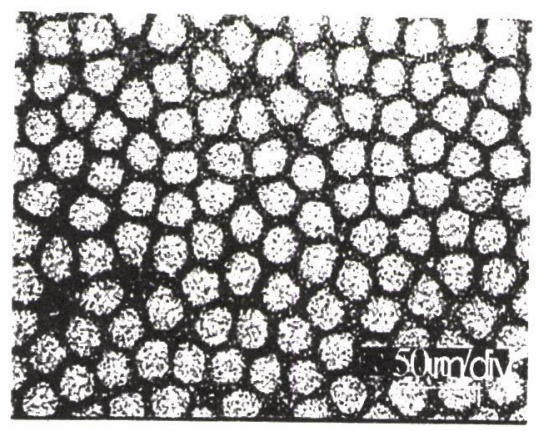

図2、新規ACFの表面写真

(Cu径18 $\mu \mathrm{m}$, ピッチ $25 \mu \mathrm{m}$ )

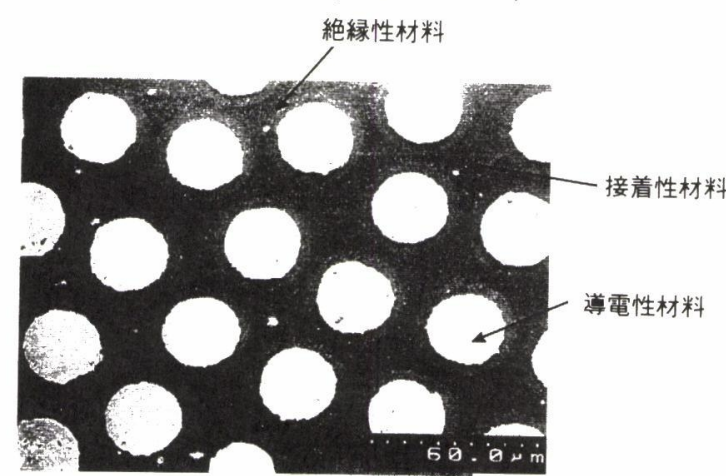

図3、新規ACF表面の画像処理写真
最表面にはNi/Au層を設ける

(2)導電性材料間の最小ピッチは $0.025 \mathrm{~mm}$ が可能

(3)導電性材料は高い熱変形温度を有する絶縁性材料で被 覆

(4)接着性材料は室温保存可能な材料を使用

我々はこのような構造により，バンプレスおよびファイ ンピッチ接続が可能になるものと考え, 新規 ACFの作成 プロセスを開発した。現在はフィルム厚, ピッチ距離，銅 柱表面状態等の最適化, ならびに接着材料, 絶縁材料等の 材料およびボンディング条件の最適化の実験を行ってい る。

以下に, 現在開発中の代表的なACFの特性を示す。

\section{4. 新規ACFの特性}

\section{1 フィルム特性}

表 2 に代表的な $\mathrm{ACF}$ 物性値を示す。

我々が開発中の $\mathrm{ACF}$ は用途により, 導電性材料, 接着 性材料, 絶縁性材料の断面積比率, 導電性材料の直径, 接 着性材料と絶縁性材料の種類を広い範囲で変化させること が可能である。

室温保存が可能な接着性材料を使用している特徵を生か して, 図 4 に示すような 2 つのボンディングプロセスをと ることが可能である。1つはチップまたはウエハにあらか じめ貼り付けた後, ウエハの場合はダイシングを経て, 基 板への実装を行うプロセス，もう 1 つは基板上にあらかじ め貼り付けた後, チップを実装する方法である。図 5 に ACFでボンディングを行ったサンプルの断面写真を示す。

\section{2 信頼性評価}

表に示したCupil-11を用いて，各種の接続信頼性評価を 行った。使用したチップ，基板については図 6 に示す。

表2. 代表的な $\mathrm{ACF}$ 物性值

\begin{tabular}{|c|c|c|c|}
\hline 項U & 評価方法 & Cupil-11 & Cupil-31 \\
\hline フィルム厚 $\left(\mathrm{T}_{\mathrm{l}}\right)$ & & $70 \mathrm{~mm}$ & $60 \mathrm{~mm}$ \\
\hline 導電性材料 & & $\mathrm{Cu}$ & $\mathrm{Cu}$ \\
\hline 導電性材料径 & micro meter & $18 \mathrm{~mm}$ & $30 \mathrm{~mm}$ \\
\hline 絶緣性:材料 & & アミドイミド & アミドイミド \\
\hline 熱変形温度 & TMA & $282^{\circ} \mathrm{C}$ & $200^{\circ} \mathrm{C}$ \\
\hline 絶緣性材厚 $\left(\mathrm{T}_{2}\right)$ & micro meter & $1.0 \mathrm{~mm}$ & $7.5 \mathrm{~mm}$ \\
\hline 接着性材料 & & イミド & ポリアミド \\
\hline 熱変形温度 & TMA & $180^{\circ} \mathrm{C}$ & $160^{\circ} \mathrm{C}$ \\
\hline 接若性材料原 $\left(\mathrm{T}_{3}\right)$ & micro meter & $5.0 \mu \mathrm{m}$ & $5.0 \mu \mathrm{m}$ \\
\hline 絶䋑性材料表面処理 & & $\mathrm{Ni} / \mathrm{Au}$ & $\mathrm{Ni} / \mathrm{Au}$ \\
\hline ACF 線膨脹倸数 $(x-y)$ & TMA & $35 \mathrm{ppm}$ & $106 \mathrm{ppm}$ \\
\hline 発牛:ガス量 & $150^{\circ} \mathrm{C} 1 \mathrm{hr}$ & $<0.5 \%$ & $<0.1 \%$ \\
\hline $\mathrm{ACF}$ 弾性摔 & DMS & $2 \mathrm{GPa}$ & $1.5 \mathrm{GPa}$ \\
\hline イオン性不純物 $\mathrm{Na}$ & & $10 \mathrm{ppm}$ & $15 \mathrm{ppm}$ \\
\hline $\mathrm{Cl}$ & & $3 \mathrm{ppm}$ & $7 \mathrm{ppm}$ \\
\hline 吸水摔 & $85^{\circ} \mathrm{C} \quad 85 \% \mathrm{RH} \quad 168 \mathrm{hr}$ & $<0.1 \%$ & $<0.1 \%$ \\
\hline
\end{tabular}




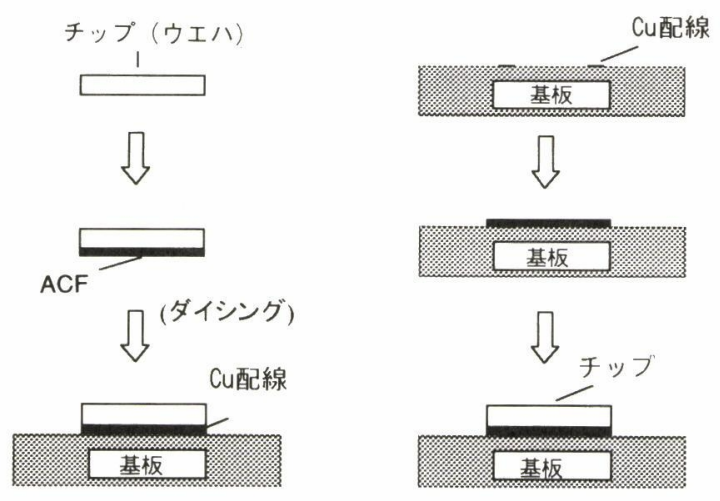

図4. 新規ACFのボンディングプロセス

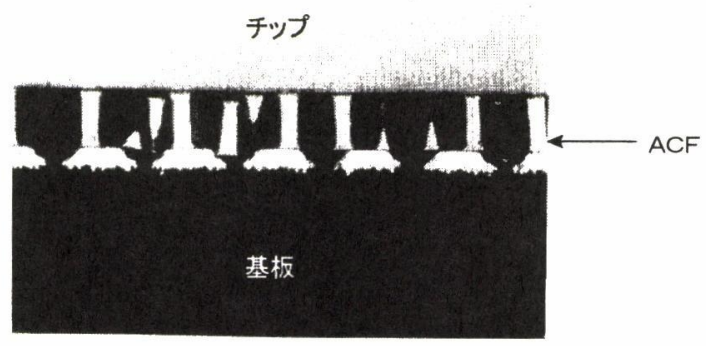

図5. ACF接続の断面写真

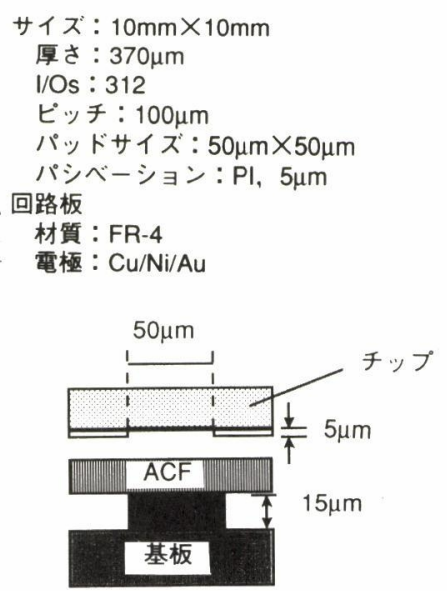

図6. 信頼性評価に使用した基板, チップ

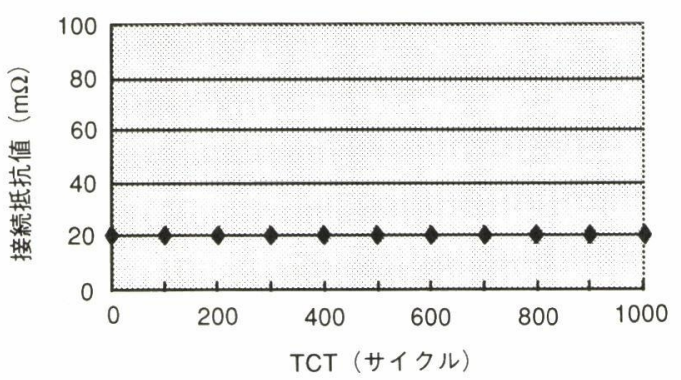

図7. TCT $\left(-25^{\circ} \mathrm{C} \sim 125^{\circ} \mathrm{C}\right)$ 結果

TCT(Thermal Cycle Test)は, $-25^{\circ} \mathrm{C} \sim 125^{\circ} \mathrm{C}$, 各 30min（気相）の条件で評価した。結果を図 7 に示す。 1000サイクル後においても, 抵抗値の上昇は認められない。

PCT(Pressure Cooker Test)は, $121^{\circ} \mathrm{C}, 100 \% \mathrm{RH}$, 2.1atmで行い，その結果を図 8 に示す。120時間後におい ても, 抵抗値の増加は認められない。

図 9 にHHBT(High temperature/High humidity Bias

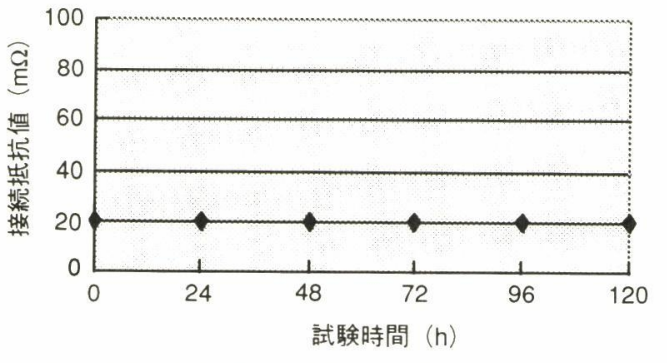

図8. PCT $\left(121^{\circ} \mathrm{C}, 100 \% \mathrm{RH}, 2.1 \mathrm{~atm}\right)$ 評価結果

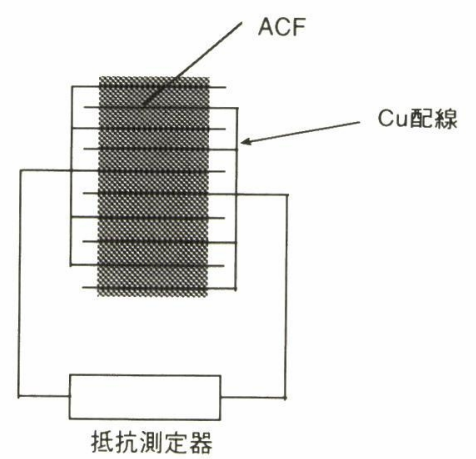

ACF : Cupil-11

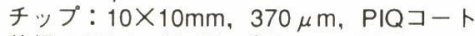
基板：FR-4，ライン /スペース50/50 $\mu \mathrm{m}$ ボンディング条件： $250^{\circ} \mathrm{C}, 10 \mathrm{~kg} / \mathrm{cm}^{2}, 10 \mathrm{sec}$ 試験条件： $85^{\circ} \mathrm{C} / 85 \% \mathrm{RH}, 5.5 \mathrm{~V}$

\section{図9. HHBTの評価方法}

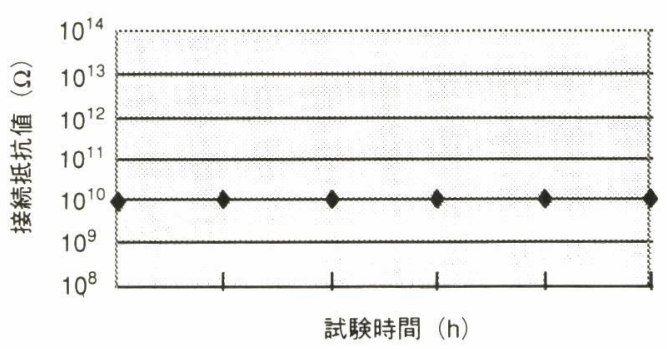

図10. HHBT評価結果

Test)の評価方法㧍よび条件を, 図10にその評価結果を示 す。ACFの中に銅柱が非常に高い密度で含まれているに もかかわらず，500時間を経てもマイグレーションによる 絶縁抵抗の低下は認められなかった。

以上のように，新規な構造を持つ ACFによる半導体素 子と基板との接続信頼性において，いずれも良好な結果が 得られた。

\section{5. 結 言}

我々が開発中の新規 ACFについて，その概略を記述し た。この材料の特徴はその構造にあり, 我々はバンプレス のファインピッチ接続の実用化に向けて, 開発速度を上げ つつある。また，この構造の特徴から，フリップチップ接 続材料以外の用途として,

(1)検査用インタポーザ (チップ, ウエハ, CSP等)

(2)高熱伝導接着フィルム

などを提案しており，評価を開始している。

（1998.11.4-受理１999.1.21-再受理） 